\title{
The fate of pharmaceuticals, steroid hormones, phytoestrogens, UV- filters and pesticides during MBR treatment
}

\author{
Revised Manuscript Submitted to
}

\section{Bioresource Technology}

June 2013

Kaushalya C. Wijekoon ${ }^{\mathrm{a}}$, Faisal I. Hai ${ }^{\mathrm{a}}$, Jinguo Kang ${ }^{\mathrm{b}}$, William E. Price ${ }^{\mathrm{b}}$, Wenshan $\mathrm{Guo}^{\mathrm{c}}$, Hao H. $\mathrm{Ngo}^{\mathrm{c}}$ and Long D. Nghiem ${ }^{\mathrm{a}, *}$

${ }^{a}$ Strategic Water Infrastructure Laboratory, School of Civil Mining and Environmental Engineering, University of Wollongong, Wollongong, NSW 2522, Australia

${ }^{\mathrm{b}}$ Strategic Water Infrastructure Laboratory, School of Chemistry University of Wollongong, Wollongong, NSW 2522, Australia ${ }^{c}$ Centre for Technologies in Water and Wastewater,

School of Civil and Environmental Engineering, University of Technology Sydney, Sydney NSW 2007, Australia

\footnotetext{
* Corresponding author: Long Duc Nghiem, Email: longn@uow.edu.au; Ph +61 242214590
} 


\begin{abstract}
This study examined the effect of molecular properties on the fate of trace organic contaminants (TrOCs) in the aqueous and solid phases during wastewater treatment by MBR. A set of 29 TrOCs was selected to represent pharmaceuticals, steroid hormones, phytoestrogens, UV-filters and pesticides that occur ubiquitously in domestic wastewater. Both adsorption and biodegradation/transformation were found responsible for the removal of TrOCs by MBR treatment. A connection between biodegradation and molecular structure could be observed while adsorption was the dominant removal mechanism for the hydrophobic $(\log D>3.2)$ compounds. Compounds with high $\log D(\log D>3.2)$ but readily biodegradable did not accumulate in sludge. In contrast, recalcitrant compounds with a moderate hydrophobicity, such as carbamazepine, accumulated significantly in the solid phase. The results provide a framework to predict the removal and fate of TrOCs by MBR treatment.
\end{abstract}

Keywords: Trace organic contaminants (TrOCs); membrane bioreactor (MBR); biodegradation; adsorption; fate and removal. 


\section{Introduction}

A large number of trace organic contaminants (TrOCs) have been detected in raw sewage, treated effluent and withdrawn sludge as well as sewage-affected water bodies all over the world. These include steroid hormones, pharmaceuticals, personal care products, surfactants, pesticides, and disinfection by products (Kümmerer, 2009; Stasinakis and Gatidou, 2010; Zhao et al., 2010; Tran et al., 2013). In recent years, several studies have also highlighted the ubiquitous occurrence of UV filters and phytoestrogens in domestic wastewater as a potential concern (Kang and Price, 2009; Gago-Ferrero et al., 2011; Liu et al., 2012), although little is known about their fate during wastewater treatment. The occurrence of TrOCs in the aquatic environment is of significant concern to public health and the environment because of the potential adverse impact on living organisms caused by TrOCs, which can include a range of estrogenic, mutagenic, endocrine disrupting and genotoxic effects (Stasinakis and Gatidou, 2010; Zhao et al., 2010; Gago-Ferrero et al., 2011). As a result, the removal of TrOCs during wastewater treatment has been the subject of many recent publications.

Appreciable removal of certain TrOCs such as natural steroid hormones and phenolic compounds by membrane bioreactor (MBR) treatment has been widely reported in the literature (Rasche et al., 1991; Vader et al., 2000; Kim et al., 2007; Cirja et al., 2008; Miège et al., 2009; Nghiem et al., 2009; Tadkaew et al., 2010; Hai et al., 2011; Boonyaroj et al., 2012; Hamid and Eskicioglu, 2012). MBR is usually operated with a long solid retention time (SRT) which can improve the removal of some TrOCs via adsorption onto the sludge and subsequent biodegradation. A long SRT can also favour the proliferation of slowly growing bacteria (such as nitrifying bacteria), thus improving the microbial diversity in the reactor and achieving better biodegradation of TrOCs (Clara et al., 2005; Reif et al., 2008; Miège et al., 2009; Radjenović et al., 2009; Navaratna et al., 2012). However, given the number of TrOCs and the diversity in their molecular properties, the efficiency of MBRs as a barrier for some TrOCs and their removal mechanisms are still poorly understood and have not been adequately studied. In addition, studies available in the literature have focussed mostly on the fate of TrOCs in the aqueous phase and little is known about the accumulation of TrOCs in sludge.

Biodegradation and/or adsorption can govern the removal of TrOCs from the aqueous phase during MBR treatment. Molecular structure is an important factor for TrOCs biodegradation. A 
previous study by Tadkaew et al. (2011) revealed the effect of physicochemical properties (namely $\log D$ ) and functional groups on the removal of TrOCs. They proposed a qualitative predictive framework which stipulates that: i) hydrophobic compounds $(\log D>3.2)$ and compounds which are hydrophilic ( $\log D<3.2)$ but possess only electron donating groups (EDGs) would achieve high removal during MBR treatment, ii) the removal efficiency of hydrophilic compounds possessing only electron withdrawing groups (EWGs) would be low, and iii) hydrophilic compounds having both EWGs and EDGs would achieve varying removal depending on the type of the functional group. Given the diverse range of emerging TrOCs, elucidation of the removal mechanisms and subsequent development of predictive tools for the extent of the removal of specific TrOCs groups is vital to avoid continuous and expensive monitoring of the fate of each individual TrOC.

Adsorption of TrOCs onto sludge is an important removal mechanism during MBR treatment. It is noteworthy that the presence of TrOCs in sludge is of concern especially in terms of their agricultural applications. Agricultural usage accounts for $50 \%$ of the biosolids production in Europe. As a result, the European Union regulates these organic compounds in sludge to secure the safety of agriculture and soil (Gago-Ferrero et al., 2011). Therefore, it is crucial to understand the removal of TrOCs from both aqueous and solid phases in wastewater treatment. There is a limited number of reported studies on removal mechanisms of TrOCs in MBR, Radjenović et al. (2009) investigated the fate and distribution of pharmaceuticals in wastewater and sewage sludge of the conventional activated sludge and MBR treatment. They identified adsorption to sludge as a possible removal pathway for several pharmaceutical compounds such as mefenamic acid, propanolol and loritidine. They suggested that MBR, yielding higher biodegradation rate due to the application of a prolonged SRT, could reduce the TrOC load in sludge. In addition, compared to the conventional activated sludge treatment, Clara et al. (2005) and Reif et al. (2008) also illustrated MBR treatment resulted in enhanced biodegradation of several groups of TrOCs (such as pharmaceuticals, fragrances and endocrine disruptive compounds) due to the prolonged SRT.

This study aimed to provide further insight to the fate of TrOCs during MBR treatment. Aqueous phase and solid phase removal of 29 compounds representing several groups of TrOCs and possessing diverse physicochemical properties were examined. The effects of hydrophobicity 
and molecular structure on their removal mechanisms were elucidated. Finally, a generalized framework for predicting the removal mechanisms and fate during MBR treatment is proposed.

\section{Materials and Methods}

\subsection{MBR system}

A laboratory scale MBR system consisting of a $5 \mathrm{~L}$ glass reactor and an external ceramic membrane module with a nominal pore size of $1 \mu \mathrm{m}$ was used. The effective area of the membrane module (NGK, Japan) was $0.09 \mathrm{~m}^{2}$. A water bath equipped with an immersion PID controlled heating unit (Julabo, Germany) was used to keep the biological reactor at a constant temperature. Peristaltic pumps (Masterflex L/S, USA) were used for feeding, recirculation, and effluent extraction. The influent pump was operated continuously to provide wastewater to the reactor. The effluent pump was operated in $15 \mathrm{~min}$ on and 15 min off cycle to provide relaxation time to the membrane module. A longer relaxation time than that in a typical MBR was used in this study to maintain a stable HRT and avoid excessive membrane fouling. The effluent flow rate was adjusted to be the same as the influent flow rate to maintain a constant reactor volume. During the experiment, the MBR was covered with acrylic sheet to minimize any loss from evaporation. The hydraulic retention time (HRT), temperature, dissolved oxygen concentration (DO) and mixed liquor $\mathrm{pH}$ were $26 \mathrm{~h}, 26.0 \pm 0.2^{\circ} \mathrm{C}, 2.4 \pm 0.3 \mathrm{mg} / \mathrm{L}$ and $7.3 \pm 0.3$, respectively. The system was operated at a longer HRT than that in a typical MBR to maintain a relatively low membrane flux and to minimise membrane fouling since the focus of the study is on the removal of trace organic contaminants. Excess sludge was withdrawn every 3-4 days to maintain the mixed liquor suspended solid (MLSS) concentration in the reactor at $5.0 \pm 0.5 \mathrm{~g} / \mathrm{L}$, resulting in an SRT of 88 days.

\subsection{Experimental protocol}

The MBR system was inoculated with sludge obtained from the biological nutrient removal reactor of the Wollongong Wastewater Treatment Plant (Wollongong, Australia). A synthetic wastewater was used to simulate medium strength domestic wastewater and to maintain a stable operating condition. The synthetic wastewater was prepared each day by diluting the concentrated stock with Milli-Q water to obtain $100 \mathrm{mg} / \mathrm{L}$ glucose, $100 \mathrm{mg} / \mathrm{L}$ peptone, 17.5 
$\mathrm{mg} / \mathrm{L} \mathrm{KH}_{2} \mathrm{PO}_{4}, 17.5 \mathrm{mg} / \mathrm{L} \mathrm{MgSO}_{4}, 10 \mathrm{mg} / \mathrm{L} \mathrm{FeSO}_{4}, 225 \mathrm{mg} / \mathrm{L} \mathrm{CH}_{3} \mathrm{COONa}$ and $35 \mathrm{mg} / \mathrm{L}$ urea (Alturki et al., 2012). The concentrated stock solution was prepared every week and kept at $4{ }^{\circ} \mathrm{C}$. Prior to the addition of the trace organic contaminants to the influent, the MBR system was acclimatised for 125 days under the above mentioned conditions.

\subsection{Model compounds}

A set of 29 emerging TrOCs was selected (Table 1) to represent pharmaceuticals, steroid hormones, phytoestrogens, UV-filters and pesticides that occur ubiquitously in domestic wastewater. Analytical grade of these compounds were obtained from Sigma-Aldrich (Saint Louis, MO, USA). A combined stock solution of all TrOCs was prepared in pure methanol and kept on $-18{ }^{\circ} \mathrm{C}$ in the dark. Once the MBR had been acclimatised, these chemicals were continually introduced into the synthetic wastewater to obtain approximately $5 \mu \mathrm{g} / \mathrm{L}$ of each compound which is similar to their occurrence in domestic wastewater (Stasinakis and Gatidou, 2010).

\subsection{Analytical methods}

\subsubsection{Basic water quality parameters}

Total organic carbon (TOC) and total nitrogen (TN) were analysed using a TOC/TN-V $\mathrm{V}_{\mathrm{CSH}}$ analyser (Shimadzu, Japan). All other basic water quality parameters relevant to the MBR process were analysed according to the standard methods for water and wastewater examination as reported in a previous study (Hai et al., 2011).

\subsubsection{Trace organic compound analysis}

TrOC concentrations in the influent and effluent samples were determined using a method previously reported by Hai et al. (2011). The method consisted of solid phase extraction (SPE) and gas chromatography followed by quantitative determination by mass spectrometry with electron ionization. The sample volume was $500 \mathrm{~mL}$ and duplicate samples were analysed each time. To determine the TrOC concentrations in the sludge, extraction method previously reported in Wijekoon et al. (2013) was used. The sludge sample was first centrifuged and the solid pellet was freeze-dried for $4 \mathrm{~h}$ using an Alpha 1-2 LDplus Freeze Dryer (Christ GmbH, Germany). The dried sludge was ground to powder and $0.5 \mathrm{~g}$ of sludge was transferred into a glass test tube. 
Methanol ( $5 \mathrm{~mL}$ ) was added to the test tube, thoroughly mixed using a vortex mixer (VM1, Ratek, Australia) for $3 \mathrm{~min}$ and ultrasonicated for $10 \mathrm{~min}$ at $40{ }^{\circ} \mathrm{C}$. The sample was centrifuged at $3270 \mathrm{xg}$ for $10 \mathrm{~min}$ (Alleegra X-12R, Beckman Coulter, USA) and the supernatant was collected in a glass beaker for further analysis. Dichloromethane $(5 \mathrm{~mL})$ and methanol $(5 \mathrm{~mL})$ were added to the remaining sludge. The whole process of mixing, ultrasonic extraction and centrifugation was repeated. The supernatants from both steps were then mixed together, Milli-Q water added up to a volume $50 \mathrm{~mL}$ and residual methanol and dichloromethane purged using nitrogen gas. Finally, Milli-Q water was added to obtain a $500 \mathrm{~mL}$ aqueous sample. This sample was then analysed using the analytical method described above, and TrOC concentrations per gram of dry sludge were calculated.

The biodegradation/transformation, adsorption, evaporation and volatilization could be possible removal mechanisms of TrOC during wastewater treatment. The loss of TrOC load due to the evaporation was minimised by covering the reactor during the experimental period (section 2.1) while the volatilization of the selected compounds was negligible given their low Henry's law constant values (Table 1). Therefore, biodegradation/transformation and adsorption were considered as potential removal mechanisms. The mass balance of each compound was conducted based on the compound load in the feed, permeate, and sludge as well as the permeate flow, MLSS concentration and the rate of sludge extraction to determine the relative contribution between biological degradation and adsorption during MBR treatment. The total feed load and the permeate load over the experimental period were calculated considering the feed/permeate volume, compound concentration and the experimental duration, while, total load in sludge was calculated considering the MLSS concentration, compound concentration, sludge wastage rate and reactor volume. Finally, the biodegradation/transformation was estimated from the difference of measured concentrations in liquid and solid phases.

\section{[TABLE 1]}

\section{Results and discussion}

\subsection{TOC/TN removal performances}

As noted earlier, the MBR system was acclimatised for 125 days before the continuous operation using TrOC-laden feed solution. Basic performance parameters including the concentrations of 
$\mathrm{NO}_{2}{ }^{-}-\mathrm{N}, \mathrm{NO}_{3}{ }^{-}-\mathrm{N}$, and $\mathrm{NH}_{4}{ }^{+}-\mathrm{N}$ in feed and permeate, TOC and $\mathrm{TN}$ removal efficiency, permeate turbidity, DO, mixed liquor volatile suspended solid (MLVSS) and mixed liquor suspended solid (MLSS) in the mixed liquor were continuously monitored to assess the operational stability of the MBR system. $\mathrm{NO}_{2}{ }^{-}-\mathrm{N}, \mathrm{NO}_{3}{ }^{-}-\mathrm{N}$, and $\mathrm{NH}_{4}{ }^{+}-\mathrm{N}$ concentrations in permeate were stable at less than $0.5 \pm 0.2 \mathrm{mg} / \mathrm{L}, 14 \pm 2 \mathrm{mg} / \mathrm{L}$ and $4.3 \pm 0.6 \mathrm{mg} / \mathrm{L}$, respectively throughout this study. The negligible $\mathrm{NO}_{2}{ }^{-} \mathrm{N}$ concentration in permeate indicated a good aerobic nitrification capacity of the MBR system and could possibly be attributed to the nitrifying bacteria-rich sludge which was used to inoculate the reactor (section 2.2). In the MBR process, the membrane can effectively retain the slow growing nitrifying microorganisms. In addition, the long SRT used in this study was also conducive to maintenance of a nitrifying bacteria-rich sludge within the bioreactor. With $164 \pm 8 \mathrm{mg} / \mathrm{L}$ of TOC and $30 \pm 2 \mathrm{mg} / \mathrm{L}$ of TN in the feed solution, TOC and TN removals were stable at $90 \pm 1 \%$ and $33 \pm 6 \%$, respectively. The low TN removal efficiency can be attributed to the absence of an anoxic chamber in our lab scale MBR which is necessary for an effective denitrification process. In this study, the permeate turbidity was below $0.6 \mathrm{NTU}$ and a MLVSS/MLSS ratio of around 0.8 was consistently observed throughout this study.

\subsection{Removal of TrOCs from the aqueous phase}

The removal efficiency of each TrOC from the aqueous phase was relatively stable over the study period (Figure 1), although a significant variation in removal was observed. All eleven hydrophobic TrOCs (i.e., $\log D_{\mathrm{pH}} 8>3.2$ ) used showed above $95 \%$ removal efficiency, with octocrylene being the only exception (removal efficiency of $88 \%$ ). On the other hand, the removal of hydrophilic TrOCs varied from as low as $27 \%$ (i.e., diclofenac) to almost complete removal (i.e., ibuprofen). Since these TrOCs possess diverse molecular structure and functional groups, it was not surprising that their removal efficiencies varied significantly. Of the 29 compounds selected in this study, four showed significantly lower removal efficiencies $(60 \%$ or below). Diclofenac was removed with the lowest level of removal (27\%) followed by atrazine (36\%), propoxur (58\%) and carbamazepine (58\%). It is noteworthy that all these four compounds are hydrophilic and possess strong EWGs such as amide and chloride in their molecular structure. Thus, the low removal efficiency could be attributed to their low hydrophobicity and more importantly the occurrence of strong EWGs in their molecular 
structure, as previously reported by Tadkaew et al. (2011). Among the selected UV-filters and phytoestrogens, formononetine, enterolactone, benzophenone and oxybenzone were highly removed (> 96\%) due to the inclusion of EDGs (hydroxyl and methyl) in their molecular structure. By contrast, the removal of octocrylene, which possesses a moderately strong EWG (cyano group), was lower (67-96\%) compared to the removal of other selected UV-filters and phytoestrogens. Similar removal of octocrylene (Liu et al., 2012), benzophenone (KasprzykHordern et al., 2009) and considerably lower removal of the selected phytoestragens (Liu et al., 2010) during conventional activated sludge treatment have been reported. However, their removal during MBR treatment scarcely reported.

In this study, better reduction of nitrogen bearing compounds (where nitrogen is bound to the cyclic structure - atrazine, primidone, metranidazole, carbamazapine, diclofenac and propoxur) in comparison to several previous studies (Alturki et al.,2010; Tadkaew et al., 2011) was observed (Figure 1). For instance, a near-complete removal of primidone was observed which was in contrast to the very low removal efficiency $(<13 \%)$ previously reported by Tadkaew et al. (2011). A higher removal of atrazine (36\%) than that reported $(<5 \%)$ in Tadkaew et al. (2011) and Alturki et al. (2010) was also observed. Notably, Bouju et al. (2008) reported the maximum removal of atrazine to date (approximately $40 \%$ ) through a genetically modified bacterial strain. Relatively higher removal of diclofenac and carbamezapine could also be noticed compared to the lower removal $(<17 \%)$ reported by Alturki et al. (2010) and Tadkaew et al. (2011) (Figure 2). Nonetheless, amitriptylene, a nitrogen bearing compound where nitrogen is bound to the aliphatic chain, showed similar removal efficiency (95\%) as reported by Tadkaew et al. (2011). Major differences between Alturki et al. (2010), Tadkeaw et al. (2011) and the current study are in the membrane type and the seed sludge (Supplementary data Table S1). Because of the development of a cake layer over the membrane during operation within an MBR, the effect of type of microfiltration/ultrafiltration membranes on TrOC removal is negligible. On the other hand, in the current study, seed sludge was obtained from a biological nutrient removal reactor of a full scale sewage treatment plant, while the seed sludge for the previous studies (Alturki et al. (2010) and Tadkaew et al. (2011) was from a conventional activated sludge treatment process. Therefore, the significant difference in the removal of atrazine and other nitrogen bearing compounds between our current and the previous studies could possibly be attributed to the microbial composition of the seed sludge. 
The MBRs could also prevent the washout of slow-growing microorganisms like nitrifiers (Clara et al., 2005). Enhanced removals of TrOCs (such as natural and synthetic steroid hormones, halogenated hydrocarbons and phenolic compounds) by nitrifying bacterial strains has been confirmed in previous studies (Rasche et al., 1991; Vader et al., 2000; Kim et al., 2007; Hamid and Eskicioglu, 2012). Furthermore, in the current study the applied SRT (88 d) was sufficiently long, which have facilitated the enhanced removal of the nitrogenous TrOCs mentioned above. Noting further the distinct behaviour of the nitrogenous TrOCs with the nitrogen molecule bound to the aliphatic chain or the cyclic structure, it is possible that removal of nitrogen bearing compounds, where nitrogen is bound to the cyclic structure, is selectively enhanced by the nitrifying microbial consortium. A detailed study on the effect of the location of nitrogen molecules in nitrogenous $\mathrm{TrOC}_{\mathrm{S}}$ on their degradation by nitrifiers would be required to substantiate this hypothesis; however, that is beyond the scope of this study. More importantly, in line with that from the available reports, our results point to the role of nitrifiers in TrOC removal enhancement.

\section{[FIGURE 1]}

\subsection{Fate of TrOCs during MBR treatment}

A stable concentration of most of the TrOC was observed in both the liquid and solid (sludge) phases during MBR treatment (Figure 2), demonstrating the stability of the TrOC removal performances of the MBR. Permeate concentrations of all hydrophobic compounds were low with octocrylene being the only exception. In contrast, the concentrations of hydrophilic compounds in permeate varied over a wide range.

\section{[FIGURE 2]}

Among the selected TrOCs, traces of some compounds (carbamazepine, diclofenac, fenoprop, ketoprofen, gemfibrozil, 4-tert butylphenol and octocrylene) were detected in the inoculating sludge even before any TrOCs were introduced to the synthetic feed, because the seeded sludge was obtained from a domestic wastewater treatment plant. Various levels of adsorption of the TrOCs on to the sludge were observed once the TrOCs had been introduced to the MBR system. Immediately after introducing the TrOCs, all compounds were detected at higher concentrations compared to their concentration in blank samples (Supplementary data Figure S4). Subsequently, 
no clear relationship was observed with TrOC concentration in sludge with time except for naproxen, diclofenac and amitriptyline. Concentration of naproxen in sludge gradually reduced with time whereas amitriptyline concentration in sludge increased with time. This could be attributed to the hydrophilicity of naproxen $\left(\log D_{\mathrm{pH} 8}=-0.18\right)$ and hydrophobicity of amitriptyline ( $\left.\log D_{\mathrm{pH} 8}=3.21\right)$. On the other hand, the variation of diclofenac concentration in sludge could be attributed the low biodegradability caused by the complex structure regardless the hydrophilicity ( $\left.\log D_{\mathrm{pH} 8}=1.06\right)$ as discussed below. A significant amount of salicylic acid, fenoprop, naproxen, diclofenac, carbamazepine amitriptyline, triclosan and octocrylene remained adsorbed to biosolids throughout the experimental period. Two factors may be responsible for the detection of the above TrOCs in biosolids namely high hydrophobicity and less biodegradability. Interestingly, despite the high hydrophobicity, most of the hydrophobic compounds presented very low solid phase concentration. Among the 11 hydrophobic compounds studied, only triclosan, octocrylene and amitriptyline were detected in sludge at significant concentrations. Triclosan was most abundant in the solid phase $(1,277 \mathrm{ng} / \mathrm{g})$ followed by octocrylene and amitriptyline. By contrast, despite their low hydrophobicity ( $\log D<3.2$ at $\mathrm{pH}$ 8), a few persistent hydrophilic compounds (fenoprop, diclofenac, and carbamazepine) were consistently detected at high concentrations in biosolids. Our results indicated that biodegradability was an important factor governing the residual amount of TrOCs in biosolids. It was also noted that stable concentration of these compounds in sludge over the experimental period could be due to the periodic discharge of sludge from the system.

Results reported in this study confirm that the removal mechanisms and the fate of TrOCs (Figure 3) are governed by their molecular properties. The concentration of the TrOCs in the solid phase increased after they had been introduced into the synthetic wastewater only if they contained EWGs in their structure and/or were hydrophobic. In fact, other than triclosan and octocrylene, the solid phase concentrations of all nine compounds with $\log \mathrm{D}$ at $\mathrm{pH} 8$ of above 3.2 but containing no EWGs in their molecular structure were negligible. On the other hand, higher concentration of triclosan and octocrylene in sludge was due to their very high $\log D$ (of 4.92 and 6.89 at $\mathrm{pH} \mathrm{8,} \mathrm{respectively)} \mathrm{and} \mathrm{the} \mathrm{presence} \mathrm{of} \mathrm{EWG} \mathrm{(i.e.} \mathrm{chloride} \mathrm{and} \mathrm{cyanide} \mathrm{group,}$ respectively) in their molecular structure. Notably, the mass balance calculation revealed that adsorption onto solid phase accounted for 50 and $26 \%$ the overall loading of triclosan and octocrylene, respectively, during MBR treatment (Figure 3). This signifies that strong EWG 
(chlorine atoms in triclosan) could cause compounds to accumulate more in sludge than the compounds with moderate EWG in their structure (cyanide group in octocrylene) even if the latter may be more hydrophobic (in this case, octocrylene (log D 6.89 at $\mathrm{pH} 8$ ) possesses more hydrophobicity than triclosan $(\log \mathrm{D} 4.92$ at $\mathrm{pH} 8)$ ). This also demonstrated that adsorption facilitated the occurrence of biodegradation of TrOCs during MBR operation where the long SRT of the MBR system enhanced the biodegradation of hydrophobic compounds due to adsorption to the sludge (Clara et al., 2005; Miège et al., 2009; Radjenović et al., 2009).

\section{[FIGURE 3]}

During MBR treatment, the concentrations of persistent hydrophilic/or moderately hydrophobic compounds (e.g. propoxur, diclofenac, carbamazepine, and atrazine) in the solid phase were low and adsorption to sludge could only account for a small fraction $(5 \%)$ of their fate (except for carbamazepine) (Figure 3). Despite being a very recalcitrant compound with moderate hydrophobicity $\left(\log D_{\mathrm{pH} 8}=1.89\right)$ due to the presence of an amide functional group (Tadkaew et al., 2011), carbamazepine, could significantly accumulate in sludge. Although the overall aqueous phase removal of carbamazepine ranged between 47 to $70 \%$ (Figure 1) the actual extent of biodegradation/transformation did not exceed $26 \%$ (Figure 3 ).

\subsection{Removal mechanisms}

Results from this study denoted a clear dependence of TrOC molecular structure on their removal mechanism and their fate in aerobic MBR. It appeared that the removal mechanisms and the fate of TrOCs were governed, in addition to hydrophobicity $(\log D)$, by the presence of EWGs or EDGs in their structure. Thus, the removal mechanism and the fate of TrOCs could be predicted by assessing the presence of EWGs and/or EDGs in their structure and their $\log D$. Based on the TrOC concentrations in aqueous and solid phases as well as the extent of their biodegradation/transformation, a generalized framework to predict the removal mechanisms of TrOCs during MBR treatment was proposed in Figure 4.

\section{[FIGURE 4]}

\section{Conclusion}

This study investigated both the solid (sludge) phase and aqueous phase removal of TrOCs and their fate during MBR treatment. The fate of TrOCs during MBR treatment was governed by 
both biodegradation and adsorption. Biodegradation was the predominant removal mechanism of the hydrophilic TrOCs from the aqueous phase. The removal of hydrophobic TrOCs from the aqueous phase could occur via adsorption. However, readily biodegradable hydrophobic TrOCs did not accumulate significantly in sludge. Additionally, recalcitrant TrOCs which are moderately hydrophobic or even hydrophilic could accumulate significantly in the sludge.

\section{Acknowledgement}

The authors would like to thank the University of Wollongong for the $\mathrm{PhD}$ scholarship support to Kaushalya C Wijekoon.

\section{References}

[1] Alturki, A., J. McDonald, S. J. Khan, F. I. Hai, W. E. Price and L. D. Nghiem (2012). Performance of a novel osmotic membrane bioreactor (OMBR) system: Flux stability and removal of trace organics. Bioresour. Technol. 113: 201-206.

[2] Alturki, A. A., N. Tadkaew, J. A. McDonald, S. J. Khan, W. E. Price and L. D. Nghiem (2010). Combining MBR and NF/RO membrane filtration for the removal of trace organics in indirect potable water reuse applications. J. Membr. Sci. 365: 206-215.

[3] Boonyaroj, V., C. Chiemchaisri, W. Chiemchaisri, S. Theepharaksapan and K. Yamamoto (2012). Toxic organic micro-pollutants removal mechanisms in long-term operated membrane bioreactor treating municipal solid waste leachate. Bioresource Technol. 113: 174-180.

[4] Bouju, H., G. Buttiglieri and F. Malpei (2008). Perspectives of persistent organic pollutants (POPS) removal in an MBR pilot plant. Desalination 224: 1-6.

[5] Cirja, M., P. Ivashechkin, A. Schäffer and P. Corvini (2008). Factors affecting the removal of organic micropollutants from wastewater in conventional treatment plants (CTP) and membrane bioreactors (MBR). Rev. Environ. Sci. Biotechnol. 7: 61-78.

[6] Clara, M., N. Kreuzinger, B. Strenn, O. Gans and H. Kroiss (2005). The solids retention time - a suitable design parameter to evaluate the capacity of wastewater treatment plants to remove micropollutants. Water Res. 39: 97-106.

[7] Clara, M., B. Strenn, O. Gans, E. Martinez, N. Kreuzinger and H. Kroiss (2005). Removal of selected pharmaceuticals, fragrances and endocrine disrupting compounds in a membrane bioreactor and conventional wastewater treatment plants. Water Res. 39: 4797-4807.

[8] Gago-Ferrero, P., M. S. Díaz-Cruz and D. Barceló (2011). Occurrence of multiclass UV filters in treated sewage sludge from wastewater treatment plants. Chemosphere 84: 1158-1165. 
[9] Hai, F. I., X. Li, W. E. Price and L. D. Nghiem (2011). Removal of carbamazepine and sulfamethoxazole by MBR under anoxic and aerobic conditions. Bioresource Technol. 102: 10386-10390.

[10] Hai, F. I., K. Tessmer, L. N. Nguyen, J. Kang, W. E. Price and L. D. Nghiem (2011). Removal of micropollutants by membrane bioreactor under temperature variation. J. Membr. Sci. 383: 144-151.

[11] Hamid, H. and C. Eskicioglu (2012). Fate of estrogenic hormones in wastewater and sludge treatment: A review of properties and analytical detection techniques in sludge matrix. Water Res. 46: 5813-5833.

[12] Kang, J. and W. E. Price (2009). Occurrence of phytoestrogens in municipal wastewater and surface waters. J. Environ. Monit. 11: 1477-1483.

[13] Kasprzyk-Hordern, B., R. M. Dinsdale and A. J. Guwy (2009). The removal of pharmaceuticals, personal care products, endocrine disruptors and illicit drugs during wastewater treatment and its impact on the quality of receiving waters. Water Res. 43: 363-380.

[14] Kim, J. Y., K. Ryu, E. J. Kim, W. S. Choe, G. C. Cha and I.-K. Yoo (2007). Degradation of bisphenol A and nonylphenol by nitrifying activated sludge. Process Biochem. 42: 14701474.

[15] Kümmerer, K. (2009). The presence of pharmaceuticals in the environment due to human use - present knowledge and future challenges. J. Environ. Manage. 90: 2354-2366.

[16] Liu, Y. S., G. G. Ying, A. Shareef and R. S. Kookana (2012). Occurrence and removal of benzotriazoles and ultraviolet filters in a municipal wastewater treatment plant. Environ. Pollut. 165: 225-232.

[17] Liu, Z.-h., Y. Kanjo and S. Mizutani (2010). A review of phytoestrogens: Their occurrence and fate in the environment. Water Res. 44: 567-577.

[18] Miège, C., J. M. Choubert, L. Ribeiro, M. Eusèbe and M. Coquery (2009). Fate of pharmaceuticals and personal care products in wastewater treatment plants - Conception of a database and first results. Environ. Pollut. 157: 1721-1726.

[19] Navaratna, D., J. Elliman, A. Cooper, L. Shu, K. Baskaran and V. Jegatheesan (2012). Impact of herbicide Ametryn on microbial communities in mixed liquor of a membrane bioreactor (MBR). Bioresource Technol. 113: 181-190.

[20] Nghiem, L. D., N. Tadkaew and M. Sivakumar (2009). Removal of trace organic contaminants by submerged membrane bioreactors. Desalination 236: 127-134.

[21] Radjenović, J., M. Petrović and D. Barceló (2009). Fate and distribution of pharmaceuticals in wastewater and sewage sludge of the conventional activated sludge (CAS) and advanced membrane bioreactor (MBR) treatment. Water Res. 43: 831-841.

[22] Rasche, R. E., M. R. Hyman and D. J. Arp (1991). Factors limiting aliphatic chlorocarbon degradation by nitrosomonas europaea: Cometabolic inactivation of ammonia monooxygenase and substrate specificity. Appl. Environ. Microbiol. 57: 2986-2994. 
[23] Reif, R., S. Suarez, F. Omil and J. M. Lema (2008). Fate of pharmaceuticals and cosmetic ingredients during the operation of a MBR treating sewage. Desalination 221: 511-517.

[24] Stasinakis, A. S. and G. Gatidou (2010). Micropollutants and aquatic environment. Treatment of micropollutants in water and wastewatr:Integrate environmental technologies series. J. Virkutyte, S. Varma R and V. Jegatheesan. London, Interantional Water Association: 1-51.

[25] Tadkaew, N., F. I. Hai, J. A. McDonald, S. J. Khan and L. D. Nghiem (2011). Removal of trace organics by MBR treatment: The role of molecular properties. Water Res. 45: 24392451.

[26] Tadkaew, N., M. Sivakumar, S. J. Khan, J. A. McDonald and L. D. Nghiem (2010). Effect of mixed liquor $\mathrm{pH}$ on the removal of trace organic contaminants in a membrane bioreactor. Bioresource Technol. 101: 1494-1500.

[27] Tran, N. H., T. Urase and T. T. Ta (2013). A preliminary study on the occurrence of pharmaceutically active compounds in hospital wastewater and surface water in Hanoi, Vietnam. CLEAN - Soil, Air, Water: doi:10.1002/clen.201300021.

[28] Vader, J. S., C. G. van Ginkel, F. M. G. M. Sperling, J. de Jong, W. de Boer, J. S. de Graaf, M. van der Most and P. G. W. Stokman (2000). Degradation of ethinyl estradiol by nitrifying activated sludge. Chemosphere 41: 1239-1243.

[29] Wijekoon, K. C., T. Fujioka, J. A. McDonald, S. J. Khan, F. I. Hai, W. E. Price and L. D. Nghiem (2013). Removal of N-nitrosamines by an aerobic membrane bioreactor. Bioresource Technol.: doi:10.1016/j.biortech.2013.1001.1057.

[30] Zhao, J.-L., G.-G. Ying, Y.-S. Liu, F. Chen, J.-F. Yang, L. Wang, X.-B. Yang, J. L. Stauber and M. S. J. Warne (2010). Occurrence and a screening-level risk assessment of human pharmaceuticals in the PearlRiver system, South China. Environ. Toxicol. Chem. 29: 1377-1384. 


\section{LIST OF TABLES}

Table 1: Physicochemical properties of the selected TrOCs.

\begin{tabular}{|c|c|c|c|c|c|}
\hline Category & Compound & $\begin{array}{l}\text { Molecular } \\
\text { Formula }\end{array}$ & $\begin{array}{l}\text { Molecular } \\
\text { Weight } \\
\text { (g/mol) }\end{array}$ & $\begin{array}{c}\text { Log } \\
D \text { at } \\
\text { pH } 8\end{array}$ & $\begin{array}{c}\text { Henry's Law } \\
\text { Constant at } \\
25^{\circ} \mathrm{C} \\
\text { (atm. } \mathrm{m}^{3} / \mathrm{mol} \text { ) }\end{array}$ \\
\hline \multirow{11}{*}{$\begin{array}{l}\text { Pharmaceutical } \\
\text { and } \\
\text { personal care } \\
\text { products }\end{array}$} & Salicylic acid & $\mathrm{C}_{7} \mathrm{H}_{6} \mathrm{O}_{3}$ & 138.12 & -1.14 & $1.42 \times 10^{-8}$ \\
\hline & Ketoprofen & $\mathrm{C}_{16} \mathrm{H}_{14} \mathrm{O}_{3}$ & 254.30 & -0.55 & $1.92 \times 10^{-13}$ \\
\hline & Naproxen & $\mathrm{C}_{14} \mathrm{H}_{14} \mathrm{O}_{3}$ & 230.30 & -0.18 & $6.08 \times 10^{-12}$ \\
\hline & Metronidazole & $\mathrm{C}_{6} \mathrm{H}_{9} \mathrm{~N}_{3} \mathrm{O}_{3}$ & 171.15 & -0.14 & $2.07 \times 10^{-12}$ \\
\hline & Ibuprofen & $\mathrm{C}_{13} \mathrm{H}_{18} \mathrm{O}_{2}$ & 206.30 & 0.14 & $5.54 \times 10^{-10}$ \\
\hline & Primidone & $\mathrm{C}_{12} \mathrm{H}_{14} \mathrm{~N}_{2} \mathrm{O}_{2}$ & 218.25 & 0.83 & $1.16 \times 10^{-14}$ \\
\hline & Diclofenac & $\mathrm{C}_{14} \mathrm{H}_{11} \mathrm{Cl}_{2} \mathrm{NO}_{2}$ & 296.15 & 1.06 & $2.69 \times 10^{-11}$ \\
\hline & Gemfibrozil & $\mathrm{C}_{15} \mathrm{H}_{22} \mathrm{O}_{3}$ & 250.30 & 1.18 & $1.83 \times 10^{-11}$ \\
\hline & Carbamazepine & $\mathrm{C}_{15} \mathrm{H}_{12} \mathrm{~N}_{2} \mathrm{O}$ & 236.27 & 1.89 & $9.41 \times 10^{-12}$ \\
\hline & Amitriptyline & $\mathrm{C}_{20} \mathrm{H}_{23} \mathrm{~N}$ & 277.40 & 3.21 & $1.24 \times 10^{-10}$ \\
\hline & Triclosan & $\mathrm{C}_{12} \mathrm{H}_{7} \mathrm{Cl}_{3} \mathrm{O}_{2}$ & 287.50 & 4.92 & $9.49 \times 10^{-6}$ \\
\hline \multirow{5}{*}{$\begin{array}{c}\text { Steroid } \\
\text { Hormones }\end{array}$} & Estriol & $\mathrm{C}_{18} \mathrm{H}_{24} \mathrm{O}_{3}$ & 288.40 & 2.53 & $1.75 \times 10^{-11}$ \\
\hline & Estrone & $\mathrm{C}_{18} \mathrm{H}_{22} \mathrm{O} 2$ & 270.36 & 3.62 & $9.61 \times 10^{-10}$ \\
\hline & $17 \alpha-$ Ethinylestradiol & $\mathrm{C}_{20} \mathrm{H}_{24} \mathrm{O}_{2}$ & 296.48 & 4.11 & $3.74 \times 10^{-10}$ \\
\hline & $17 \beta-$ Estradiol & $\mathrm{C}_{18} \mathrm{H}_{24} \mathrm{O}_{2}$ & 272.38 & 4.14 & $1.17 \times 10^{-9}$ \\
\hline & $\begin{array}{l}17 \beta-\text { Estrodiol- } 1 \\
\text { acetate }\end{array}$ & $\mathrm{C}_{20} \mathrm{H}_{26} \mathrm{O}_{3}$ & 314.42 & 5.11 & $2.15 \times 10^{-9}$ \\
\hline \multirow{6}{*}{ Pesticides } & Clofibric acid & $\mathrm{C}_{10} \mathrm{H}_{11} \mathrm{ClO}_{3}$ & 214.64 & -1.29 & $2.91 \times 10^{-10}$ \\
\hline & Fenoprop & $\mathrm{C}_{9} \mathrm{H}_{7} \mathrm{Cl}_{3} \mathrm{O}_{3}$ & 269.51 & -0.28 & $4.72 \times 10^{-12}$ \\
\hline & Propoxur & $\mathrm{C}_{11} \mathrm{H}_{15} \mathrm{NO}_{3}$ & 209.24 & 1.54 & $5.26 \times 10^{-7}$ \\
\hline & Pentachlorophenol & $\mathrm{C}_{6} \mathrm{HCl}_{5} \mathrm{O}$ & 266.38 & 2.19 & $1.82 \times 10^{-7}$ \\
\hline & Atrazine & $\mathrm{C}_{8} \mathrm{H}_{14} \mathrm{ClN}_{5}$ & 215.68 & 2.64 & $5.22 \times 10^{-8}$ \\
\hline & Ametryn & $\mathrm{C}_{9} \mathrm{H}_{17} \mathrm{~N}_{5} \mathrm{~S}$ & 227.33 & 2.97 & $3.67 \times 10^{-9}$ \\
\hline \multirow{2}{*}{$\begin{array}{l}\text { Industrial } \\
\text { chemicals }\end{array}$} & 4-tert-butyphenol & $\left(\mathrm{CH}_{3}\right)_{3} \mathrm{CC}_{6} \mathrm{H}_{4} \mathrm{OH}$ & 150.22 & 3.39 & $7.51 \times 10^{-6}$ \\
\hline & 4-tert-octylphenol & $\mathrm{C}_{14} \mathrm{H}_{22} \mathrm{O}$ & 206.33 & 5.18 & $8.67 \times 10^{-6}$ \\
\hline \multirow{2}{*}{ Phytoestrogens } & Formononetin & $\mathrm{C}_{16} \mathrm{H}_{12} \mathrm{O}_{4}$ & 268.26 & 1.81 & $2.91 \times 10^{-10}$ \\
\hline & Enterolactone & $\mathrm{C}_{18} \mathrm{H}_{18} \mathrm{O}_{4}$ & 298.33 & 1.88 & $8.07 \times 10^{-13}$ \\
\hline \multirow{3}{*}{ UV filters } & Benzophenone & $\mathrm{C}_{13} \mathrm{H}_{10} \mathrm{O}$ & 182.22 & 3.21 & $1.31 \times 10^{-6}$ \\
\hline & Oxybenzone & $\mathrm{C}_{14} \mathrm{H}_{12} \mathrm{O}_{3}$ & 228.24 & 3.42 & $1.22 \times 10^{-8}$ \\
\hline & Octocrylene & $\mathrm{C}_{24} \mathrm{H}_{27} \mathrm{~N}$ & 361.48 & 6.89 & $3.38 \times 10^{-9}$ \\
\hline
\end{tabular}

Note: Henry's law constant values were calculated as: Henry's law constant at $25{ }^{\circ} \mathrm{C}$ $\left(\mathrm{atm} . \mathrm{m}^{3} / \mathrm{mol}\right)=$ Vapour pressure $\times$ molecular weight $/$ water solubility. Molecular formulas, molecular weight, $\log D$, vapour pressure and water solubility values were from Scifinder Scholar. 


\section{LIST OF FIGURES AND TABLES CAPTIONS}

Figure 1: Average removal efficiency of the selected trace organic contaminants by MBR; error bars represent the standard deviation calculated from duplicate samples taken once a week for five weeks. Operating conditions of MBR are presented in section 2.1.

Figure 2: Average concentrations of the selected trace organic contaminants in (a) feed and permeate streams, and (b) sludge of MBR system. Error bars of the feed and permeate data represent the standard deviation of duplicate samples taken once a week for five weeks. Error bars of sludge data represent the standard deviation of duplicate samples taken once a week for four weeks.

Figure 3: Fate of the selected trace organic contaminants during MBR treatment. Operating conditions of MBR are presented in section 2.1.

Figure 4: TrOC removal mechanisms during MBR treatment. Percentages of biodegradation and accumulation in sludge are with respect to the influent loading. EWGs and EDGs represent the electron withdrawing functional groups and electron donating functional groups, respectively. 

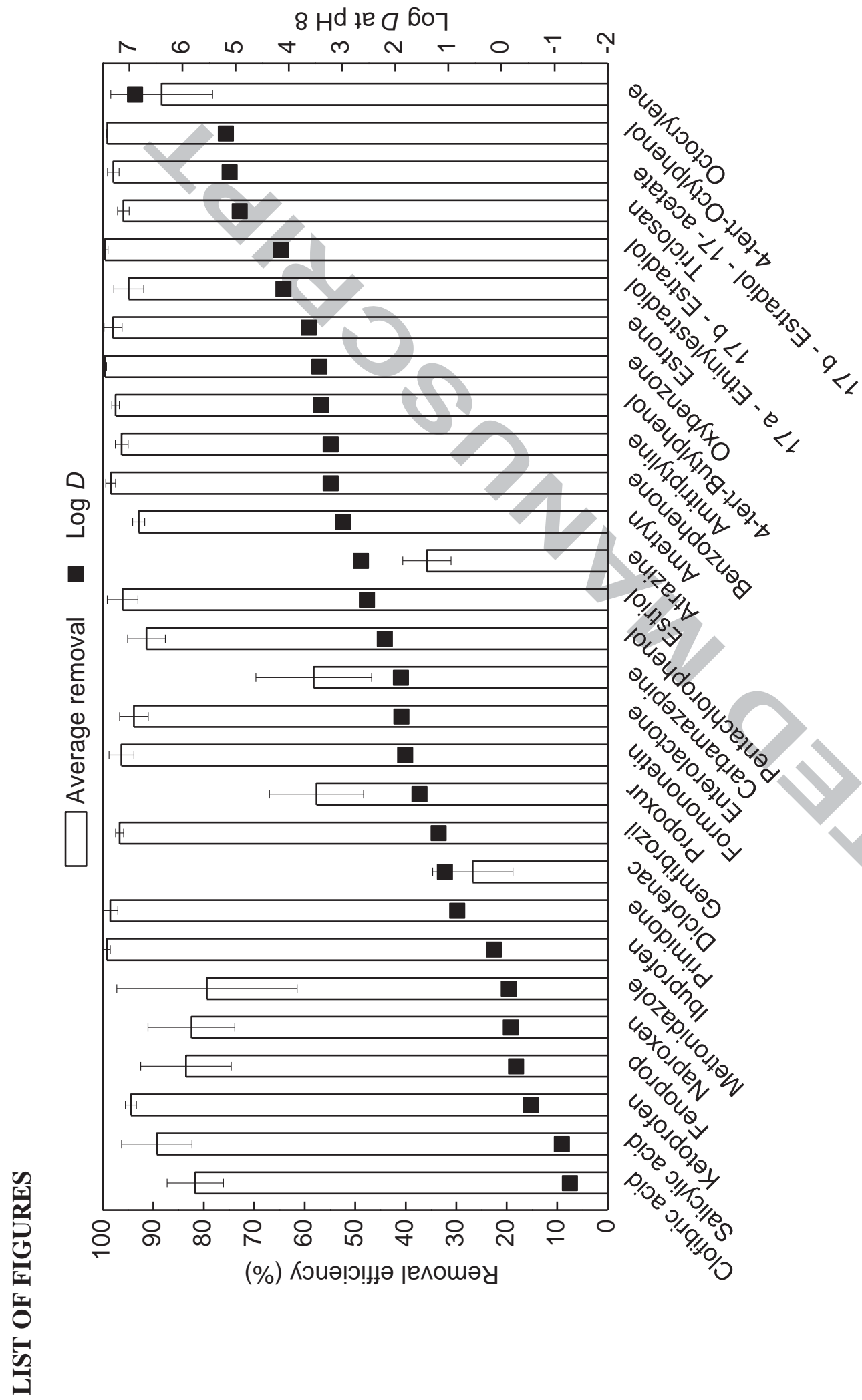

$\infty$ 


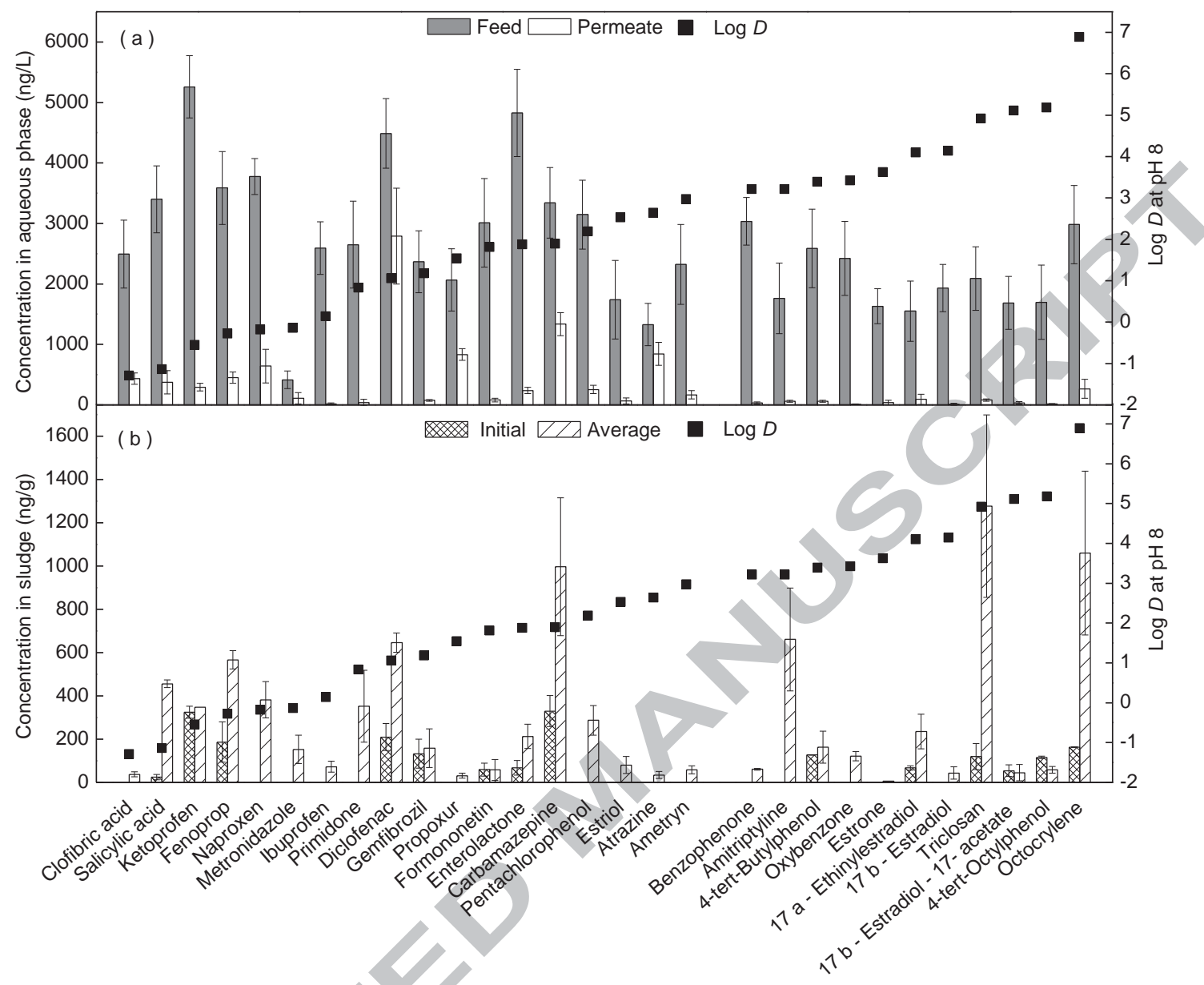

Figure 2 


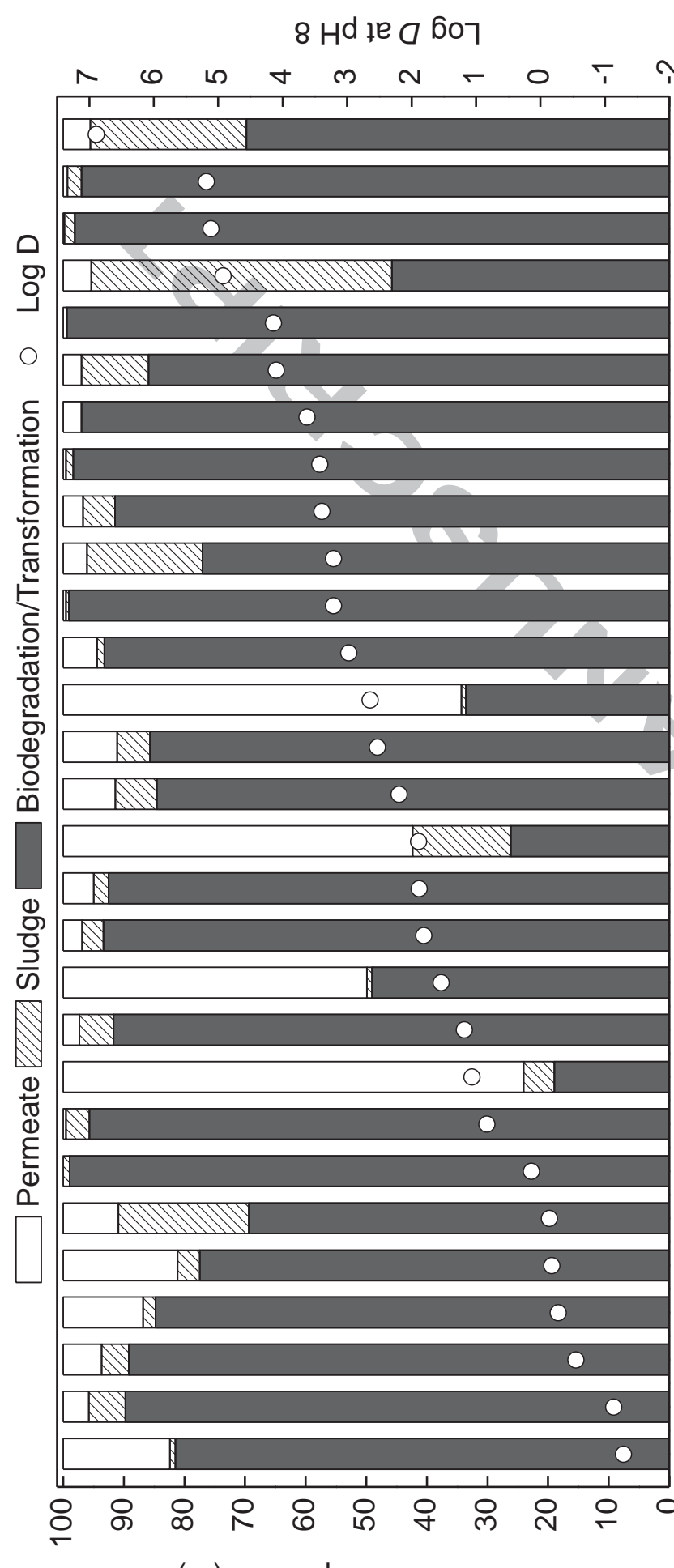

(\%) spunodmos to uo!̣nq!!ıs!

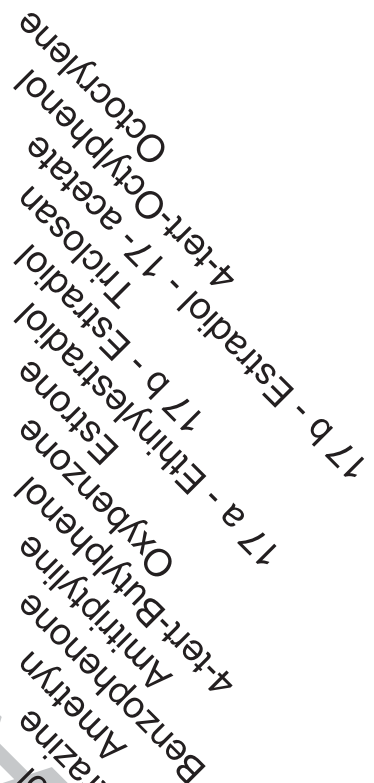




\section{Trace organic contaminants}

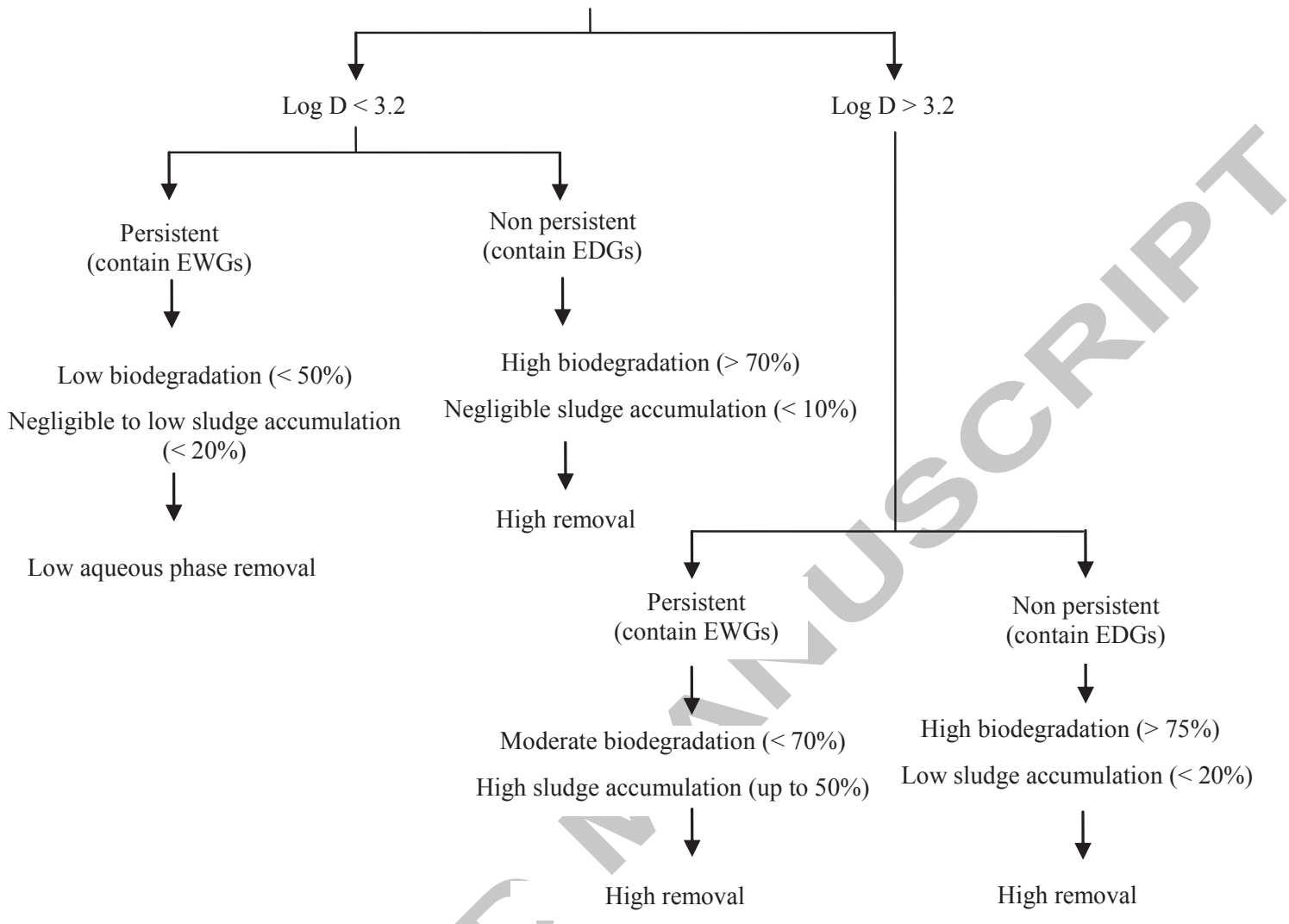

Figure 4 


\section{RESEARCH HIGHLIGHTS}

- Both biodegradation and adsorption govern the removal of TrOC by MBR

- Biodegradation is the most important removal mechanism of hydrophilic compounds

- Adsorption aids the degradation of hydrophobic compounds

- Hydrophobic \& persistent TrOC accumulated in the sludge during MBR treatment 